\title{
The Polymorphism of Time
}

\author{
Patrice F Dassonvillle* \\ Author of the Invention of Time and Space: Origins, Definitions, Nature, Properties, France
}

*Corresponding author: Patrice F Dassonvillle, Department of Philosophy, Author of the Invention of Time and Space: Origins, Definitions, Nature, Properties, France

Submission: 眥April 17, 2018; Published: 眥 April 24, 2018

\section{Introduction}

The knowledge of time is parasitized by numerous metaphors, stereotypes and preconceived ideas, which prevent one to define it. The efficient way to approach this notion is to look for its geohistorical origins. Indeed, archaeology and ancient literature reveal that time appeared in the form of what is now called units. Time units are concepts which came from the interpretation of certain natural phenomena, like the lunation, the return of seasons, the alternation of days and nights, the flood of the Nile, etc.

\section{The Emergence of Time Units}

The oldest time unit is the lunar month, which was invented between 4800 and 4500 years ago by the Sumerians [1]. The way they were using it, leads to a basic definition: The lunar month is a concept which corresponds to a lunation. It must be emphasized that a lunation is a natural phenomenon, while the lunar month is an interpretation of this phenomenon: a concept. All units of time can be defined in the same way.

According to the Roman Consul Ausonius in 379 AD [2]: The year is a concept which corresponds to the return of the seasons. A more accurate definition: The year is a concept which corresponds to one terrestrial revolution.

a. In other words, the phenomenon (a terrestrial revolution) leads to a concept (the year).

b. It is crucial to understand that the lunar month is not the duration of a lunation and that the year is not the duration of a terrestrial revolution.

c. In addition, time and duration are semantic nuances of the same concept.

\section{Definition of Time}

The definition of time is drafted, compared to changes or phenomena, in the same way as that of the units. Four examples:

a. The duration of a race is what the stopwatch does between departure and arrival. It's important to understand that we don't measure the duration of the race: we watch the clock; the result is called duration of the race. b. The duration of the travel is what the clock of the railway station does simultaneously.

c. The duration of an event is what the clock does between the beginning and the end of the event. Contrary to the everyday language, there is no measure of duration.

d. Time is what a clock does between two states of the configuration sun / earth. Contrary to thought habits, it's not a measure of time.

We can now draft a general definition of time compared to the state of any system

a. Time is what a clock does simultaneously between two states of any system.

A state change of a system, which is a phenomenon, leads to the invention of time, which is a concept. Therefore time can be expressed in relation to the state of any system.

\section{A Polymorphous Concept}

These definitions look quite poor, but they lead to some interesting theoretical extensions which confirm that time is not a phenomenon:

a. Time is not a state variable, because it contains no information on the system concerned.

b. Time has no physical properties; instead, it has mathématical properties which are narrowly related to the definitions:

- In any circumstance, time is irreversible, because states are irreversible.

- In classical physics, it is continuous, determinist and invariant.

- In statistical physics, it is invariant, stochastic and continuous.

- In quantum physics, it is invariant, stochastic and discontinuous. 
- In Relativity, it is continuous, determinist and covariant.

In the black hole theory of Hawking [3], it is imaginary. For example we can draft a definition of the imaginary time:

The imaginary time is a concept corresponding to what separates two imaginary states of a system inside a black hole.

Time can't be subjected to physical experiences, because it's a concept. Therefore, it is not observable and not measurable. For example, the relativistic experiences are done on the states of the relativistic systems, instead of time.

\section{Conclusion}

Time is an intermediate parameter between something we know (a clock) and a phenomenon we don't know (the state of a system). It is an efficient invention of thought, although Einstein questioned himself about a theory without time and space [4]. In the years to come, we'll see if the non-phenomenology of time has an impact on the theoretical search.

\section{References}

1. Conteneau G (1937) La civilisation d'Assur et de Babylone-Payot.

2. Quet MH (2006) The crisis of the roman empire from marcus aurelius to constantinus. La Crise de L'Empire Romain de Marc Aurèle à Constantin, Presse de l'Université Paris Sorbonne, Paris, France.

3. Hawking S, Penrose R (1996) The nature of space and time, Princeton University Press, NJ, USA.

4. Klein E (2009) Le facteur temps ne sonne jamais deux fois. Champs Sciences. (c) (i) Creative Commons Attribution 4.0 International License

For possible submissions Click Here

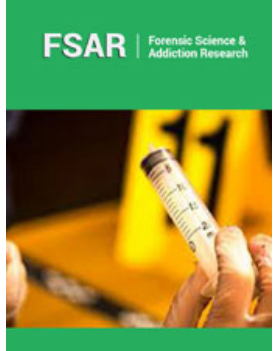

\section{Forensic Science \& Addiction Research}

\section{Benefits of Publishing with us}

- High-level peer review and editorial services

- Freely accessible online immediately upon publication

- Authors retain the copyright to their work

- Licensing it under a Creative Commons license

- Visibility through different online platforms 